\title{
E-BUSINESS - A CONTEMPORARY REALISTIC FORM OF SUCCESSFUL BUSINESS
}

\author{
Ovidiu Leonard Turcu \\ "Vasile Alecsandri" University of Bacău \\ t_ovidiu@softhome.net \\ Andreea Feraru \\ "Vasile Alecsandri" University of Bacău \\ andreea_feraru26@yahoo.com
}

\begin{abstract}
Nowadays, businesses are founded on the law of excluded middle and have to make a choice between two paths: they can either choose to evolve and keep pace with the technological trends, or to stagnate and wither just like a flower without water does, and so they become useless - both ways can be probable in the current economic context. Together with the technological evolution of the world, a new type of business has emerged on the business market, namely electronic business. Numerous websites and companies which deal with online sales are present on the market. Whether they organise online auctions or offer access to information pages or databases in exchange for payment, electronic businesses represent a new manner of doing business, a domain which is currently expanding.
\end{abstract}

\section{Keywords}

business; economy; intangible resources; e-commerce; e-business

\section{JEL Classification}

F15; O10; M10

The new economy (also called digital economy) is based on the improvements of the digital revolution and the management of information industry, which have a number of specific attributes: they can be differentiated, individualized and personalized incessantly, they can be transmitted to a large number of people who are connected to a network and they can be obtained rapidly. If these items of information become available to the public and are transparent, they can help people know a situation better and thus make better decisions. The organisations of the New Economy tend to be flat, decentralized and open to employees' initiatives.

The unprecedented development of information technologies over the last twenty years, which has been determined by the necessity to store and rapidly transmit information at very low prices, has revolutionized global commerce, direct or retail commerce, thus redefining the classical principles of marketing. Nowadays, the term "electronic commerce" is synonymous with profit increase. Commerce, within the process of managing a business, represents an activity that generates value, using the Internet as support or specific software programmes.

Numerous firms use the Internet for advertising purposes and online marketing is an opportunity to create the image of a firm and to attract customers. Companies convey technical information and use the web page as a platform for the announcement of news. Employing their own website as a store, they can offer products and receive orders.

The word Internet first appeared in 1965 and was developed by an agency dealing with research projects, namely Defense Advanced Research Projects Agency (DARPA) of the U.S. Department of Defense. As the word origin shows, the Internet 
is an interconnected network linking or interconnecting tens of millions of computers around the world. The population of the world in December 2012 exceeded 7 billion people, out of which 2.4 billion people are connected to the Internet, as shown in Figure 1.

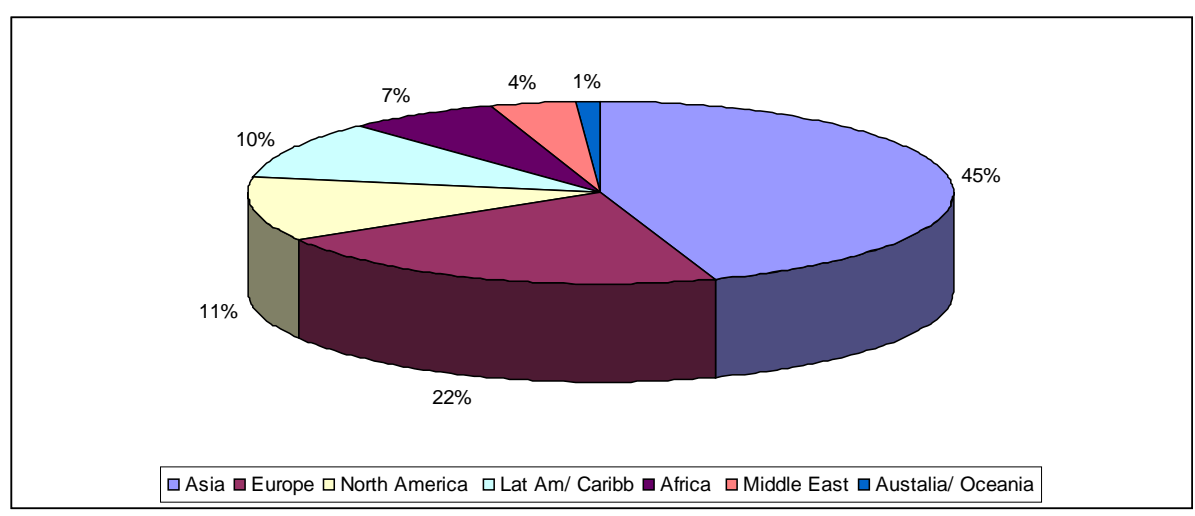

Figure 1 The world's population is connected to the internet

Source: Internet statistics in the world- www.internetworldstats.com

Table 1 Population statistics and Internet use in the world

\begin{tabular}{|c|r|r|r|}
\hline \multicolumn{4}{|c|}{ Population statistics and Internet use in the world, as of 30 June 2012} \\
\hline World regions & \multicolumn{1}{|c|}{ Population } & \multicolumn{1}{|c|}{ Internet users } & $\begin{array}{c}\text { Increase } \\
\mathbf{2 0 0 0}-\mathbf{2 0 1 2}\end{array}$ \\
\hline Africa & & & $3606.7 \%$ \\
\hline Asia & $3,073,380,925$ & $167,335,676$ & $841.9 \%$ \\
\hline Europe & $820,918,446$ & $1,076,681,059$ & $393.4 \%$ \\
\hline Middle East & $223,608,203$ & $90,000,455$ & $2629.9 \%$ \\
\hline North America & $348,280,145$ & $273,785,413$ & $153.3 \%$ \\
\hline Latin America & $593,688,638$ & $254,915,745$ & $1310.8 \%$ \\
\hline Australia & $35,903,569$ & $24,287,919$ & $218.7 \%$ \\
\hline Total in world & $7,017,846,922$ & $2,405,518,376$ & $566.4 \%$ \\
\hline
\end{tabular}

Source: Internet statistics in the world - www.internetworldstats.com

In Romania, out of the total population of 21.848 .504 people, $44.1 \%$ of them had Internet access in June 2012, which means a total number of 9.642 .383 people, according to the data offered by internetworldstats.com. It can be easily observed that the Internet's popularity is continuously and significantly increasing and easy and quick access to information has become a necessity for human life.

We cannot deny the fact that this evolution has a major impact on the economy with regard to: the creation of new business models, the diversification of existing ones, or the growth of the labour market's potential and its occupancy rate in the future. Due to this diversity of the market, which undergoes continuous change and comprises a large number of service suppliers, it is necessary to allow enterprises (especially small- and medium-sized companies) to have access to a 'source' where they could find the appropriate support for the application of the electronic commerce solutions 
to their own activity. A single person now has the capacity to run an entire business and work from home in front of the computer.

If in the industrial era people like Henry Ford or Thomas Edison represented the group of billionaires, nowadays things have changed. In the information age, people like Bill Gates, Michael Dell and the founders of Internet companies have become young millionaires or even billionaires. These young people will soon surpass the well-known businessman Bill Gates in matters of wealth. This fact results from the power of the transition from the industrial to the informational era.

This also entails that the online trading of goods and services represents an extension of current commerce. This extension of traditional commerce to include online commerce greatly impacts the economy, in relation to aspects concerning the setting up of new enterprises, the diversification of existing ones, or the labour market potential and its future increase in occupancy rates. Online commerce is not restricted by state frontiers; however, it depends on the existence or absence of computer networks. Online commerce allows even small suppliers, irrespective of their geographical origin, to be omnipresent and do business all around the world. Online commerce positively influences the activity of small and medium enterprises and also supports customers' choices by offering them a wide range of options.

For certain observers of the phenomenon, electronic commerce has the same contents as electronic business or e-Business and makes reference to any type of financial transaction which uses information technology. Others consider that the notion of "electronic commerce" covers the complete sales circuit, including marketing and the act of selling as such. Still, there are analysts who believe that electronic commerce represents any type of commercial transaction which is performed electronically for the purchase of tangible products (such as book, CDs, travelling tickets) or intangible ones (like software, tourist services etc.).

However, mention should be made that electronic commerce (e-COMMERCE) must not be confused with electronic business (e-BUSINESS). These two terms must be understood correctly because they represent two different concepts. Electronic commerce is the term used when describing the process of transacting goods or services on the Internet. On the other hand, electronic business involves the fundamental transformation of classical business mechanisms into a digital network based on the Internet. The difference between the two concepts derives from the degree in which an organisation transforms its operations and processes into digital mechanisms via the Internet. Electronic business can include any process carried out by a firm by means of employing the Internet, including internal operation such as staff training.

Electronic commerce, as compared to electronic businesses, is quite easy to implement because it involves three types of integration:

1. Vertical integration of existing web interfaces corresponding to classical transactional processes;

2. Integration of companies which possess client or supplier websites or intermediary websites such as virtual markets;

3. Integration of technological processes that correspond to managing client orders and client support.

A reference model for electronic business, which is shown in Figure 2, creates the framework for the quantitative approach of the problem and defines conceptually the e-business activities in order to identify improvement opportunities. The reference model consists of four levels, which are grouped into two main blocs/layers. The superior layer focuses on the nature of the business and processes that provide the services offered by the website. The inferior layer concentrates on the manner in which clients interact with the website and the orders they make by means of the 
resources offered by the infrastructure. Each level of the reference model is associated with two large classes, namely descriptors and metrics (measure system), which are employed for the quantitative characterisation of the level.

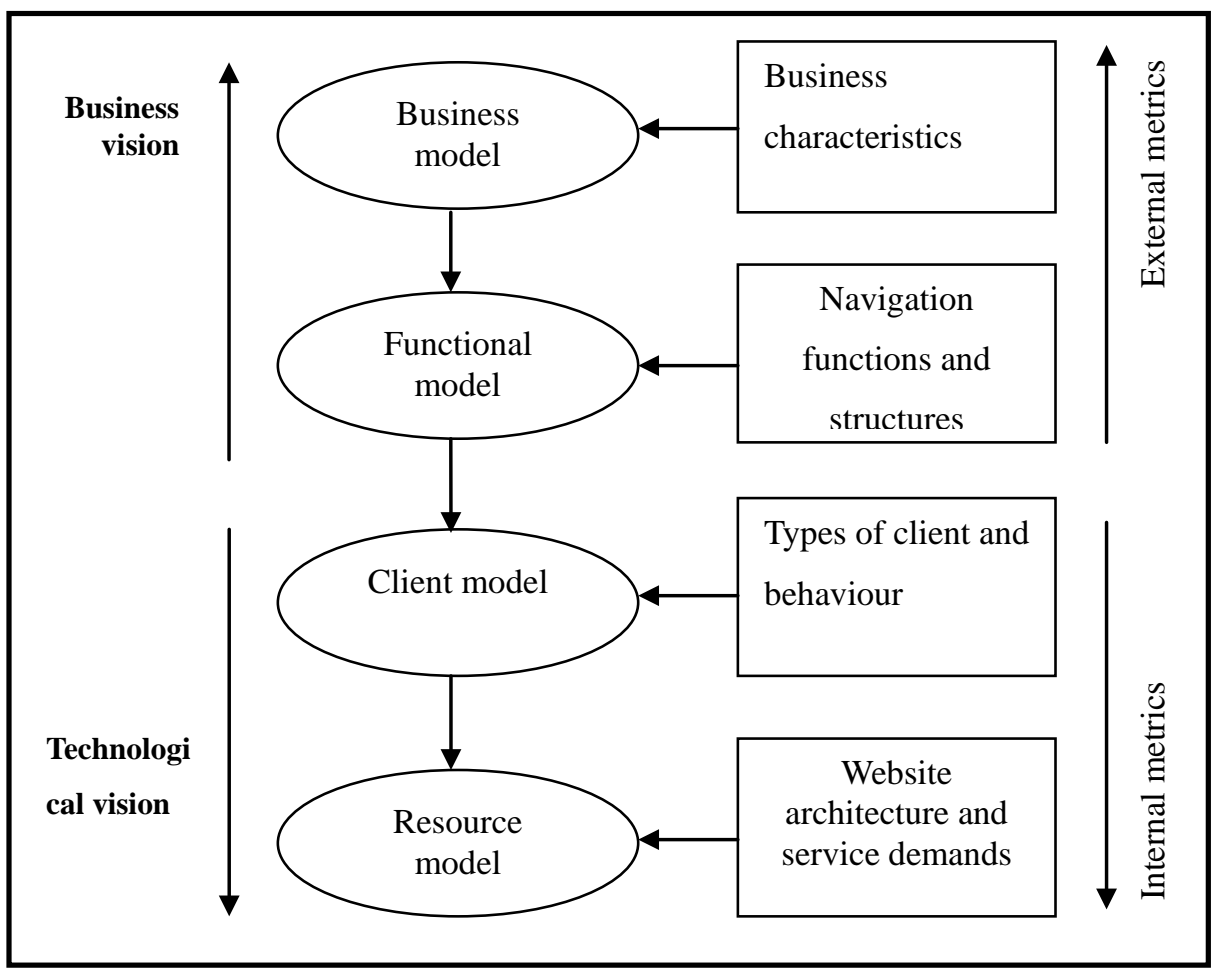

Figure 2 The Reference model for e-business

Source: own illustration

From another viewpoint, e-commerce and e-business have a set of common characteristics:

- Enhancing processes which deliver value;

- Lowering costs and increasing companies' profits;

- They use an infrastructure that consists of: databases, applications, servers, security, management instruments and systems;

- They involve the creation of new value chains linking the company, clients and suppliers;

- $\quad$ They include major organisational changes (potentially destructive ones).

The risks of failure or of limited success consequences can be much higher in case of electronic business than for electronic commerce. Thus, a wise decision could be the progressive implementation of eCommerce processes, and only after that should the business be transformed into an eBusiness. Quick changes can be disastrous for the future.

The digital economy or the new economy can be defined as an economy that is based on digital technology, including digital communication networks, software, computers etc. The concept of digital economy also comprises electronic commerce and electronic businesses. Table 2 presents the various forms of commerce and its evolution towards electronic commerce. 


\section{Table 2 Forms of electronic commerce}

\begin{tabular}{|l|l|}
\hline $\begin{array}{l}\text { Brick and mortar } \\
\text { business types }\end{array}$ & $\begin{array}{l}\text { The classical model of classical businesses in which all the } \\
\text { business is conducted exclusively off-line. Physical } \\
\text { products are sold, products which are manufactured by } \\
\text { means of physical processes. }\end{array}$ \\
\hline $\begin{array}{l}\text { Click and mortar } \\
\text { business }\end{array}$ & $\begin{array}{l}\text { The business type where organisations carry out a number } \\
\text { of on-line activities, but the primary activity consists in } \\
\text { physical production. }\end{array}$ \\
\hline Virtual business & $\begin{array}{l}\text { The model of organisations in which the economic } \\
\text { operations are conducted exclusively in the virtual world - } \\
\text { via the Internet. }\end{array}$ \\
\hline $\begin{array}{l}\text { Electronic market } \\
\text { (eMarketplace) }\end{array}$ & $\begin{array}{l}\text { A virtual market where buyers and sellers meet in order to } \\
\text { exchange goods, services, money or information. }\end{array}$ \\
\hline
\end{tabular}

In reality, the eBusiness concept means much more than electronic commerce. The difference between the two could be that the term eBusiness defines the strategy, whereas eCommerce represents a part of this strategy - eBusiness. The latter aims at strengthening relations with clients and partners, as well as improving efficiency by means of various strategies.

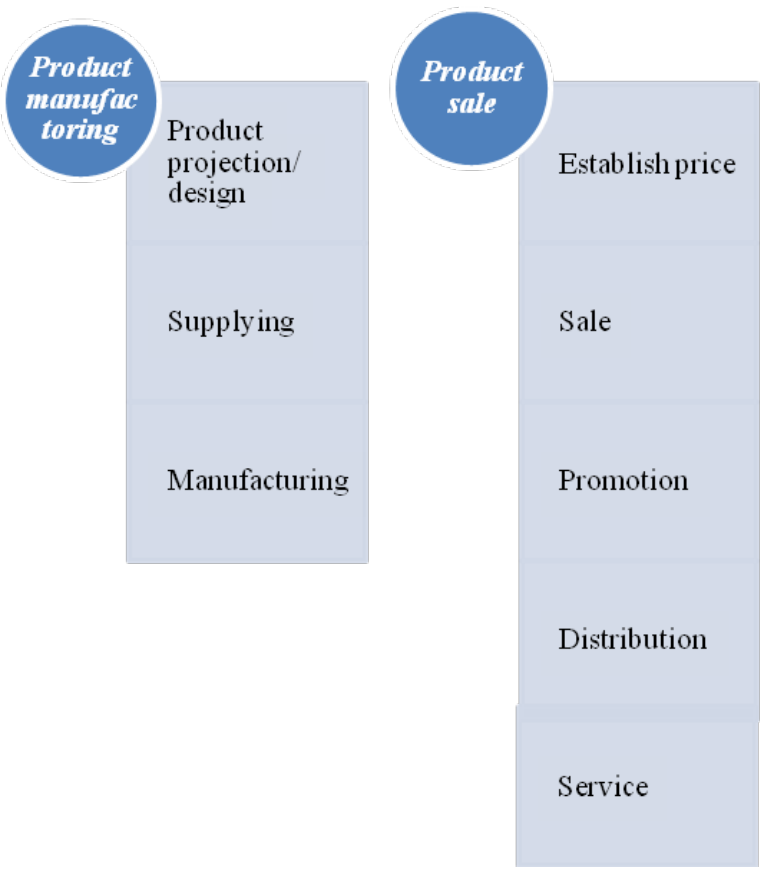

Figure 3 The succesion of the traditional process

Source: "Marketing management", Kevin Lane Keller, ed. Pearson Education, 2009 

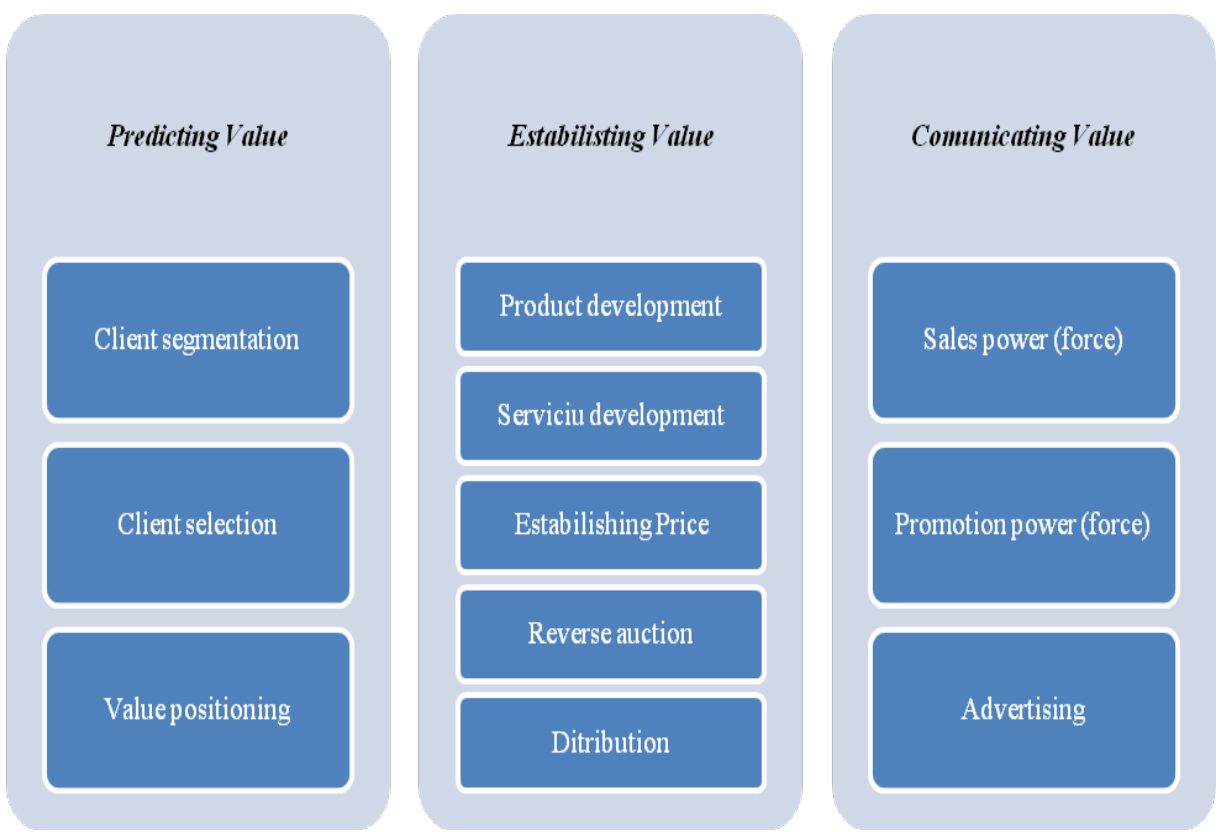

Figure 4 The succesion of creating \& delivering value

Source: "Marketing management", Kevin Lane Keller, ed. Pearson Education, 2009

A business model which uses the Internet can be defined as a type of architecture for a product, service or information flow, including the description of participants in the business, their roles and income/revenue sources. For instance, among the most popular models which generate revenue for companies we find:

a) Charging fees for commercials (adwords.google.com);

b) Selling goods and services (for example www.emag.ro - selling products, www.bt24.ro - banking services);

c) Selling digital contents (www.apple.com/itunes/);

d) Taxing the processing of transactions which are conducted by two web parties (www.sagepay.com).

The choice of the appropriate model can be made after several aspects are clarified, such as:

- $\quad$ the aim and mission of the business;

- $\quad$ the business target;

- measurable objectives;

- market size;

- $\quad$ whether the electronic market is open or restricted to certain groups;

- $\quad$ income/revenue model.

Electronic commerce is not solely restricted to the Internet; it also includes a large number of applications in the system: videotext, teleshopping, off-line environment, sales catalogues on CDs, networks owned by corporations etc.

\section{Conclusions}

In conclusion, we can point out that eBusiness comprises the electronic means used by a firm in order to manage the business, whereas eCommerce clearly establishes the methods used by the company website in order to facilitate the selling or purchasing of products online. ePurchasing involves the acquisition of products, information or 
services, generally via the Internet. This possibility of transferring the buying process to the virtual environment can generate significant profit for the companies that apply the method.

Some of the advantages created by electronic businesses include: eliminating market access barriers, reducing the possibility of purchasing replaceable products, reducing marketing costs by augmenting the power of sales markets, increasing the informational density among participants in the virtual market, both quantitatively and qualitatively, producing advantages by reducing costs for the collection, storage, processing and transmission of data, which also leads to increased levels of accuracy, promptness and topicality concerning the information.

Currently, a number of firms have become well known in the Romanian business environment, such as eMag.ro and Okazii.ro. These sites represent two business models that have successfully combined electronic platforms with physical products, so which is the result? A gigantic matchless business!

\section{References}

C.R.C.E. (2000), Secretele comertului electronic. Ghid pentru exportatoriîntreprinderi mici şi mijlocii, Interational Trade Center UNCTAD/WTO, Geneva.

Curac, Daniel, Drăgan, Florin (2004), Sisteme informatice pentru comert electronic, Timişoara, Editura Orizonturi universitare.

John Allen Coord. (1997), Ghidul întreprinzătorului particular, Bucureşti, Editura Tehnică.

Kenneth, C. L. (2004), E-commerce - business, technology, society, Pearson Education.

Manzoor, Amir, (2010), E-commerce: an introduction, Editura LAP Lambert Acad.

Middleton, John (2009), Maeştrii afacerilor online, Bucureşti, Editura Meteor Press.

OECD (2000), E-commerce for Development Prospects and Policy Issues, Technical Paper, no.164.

Oprean, D., Racoviţan, D. M., Oprean, V., Rusu, L. (2007), Managementul afacerilor pe Internet, Editura Risoprint, Cluj-Napoca. 